\title{
Berberine inhibits the proliferation of colon cancer cells by inactivating Wnt/ $\beta$-catenin signaling
}

\author{
KE WU, QIUJUN YANG, YUQIN MU, LONGYANG ZHOU, YINZI LIU, QIXIN ZHOU and BAICHENG HE \\ Department of Pharmacology, Chongqing Medical University, Chongqing 400016, P.R. China
}

Received January 2, 2012; Accepted March 9, 2012

DOI: $10.3892 /$ ijo.2012.1423

\begin{abstract}
Colon cancer is one of the most common malignancies, mainly initiated by the abnormal activation of Wnt/ $\beta$-catenin signaling. In this study, we investigated the proliferation inhibitory effect of berberine on colon cancer cells and the molecular basis underlying this effect. With the viability, apoptosis and cell cycle assay, we demonstrated that berberine can inhibit proliferation, induce apoptosis and cell cycle arrest in colon cancer cells. In in vivo investigation, we demonstrated that berberine can prevent the colon cancer formation initiated by dimethylhydrazine (DMH) and dextran sodium sulfate (DSS) in rats. We employed Western blotting, reverse transcription and polymerase chain reaction, special antagonist, overexpression and knockdown techniques to dissect the possible molecular mechanisms mediating the function of berberine. We found that the protein levels of $\beta$-catenin in the nucleus and cytoplasm were all reduced after treating the colon cancer cells with berberine, and this may not result from accelerating the degradation of $\beta$-catenin in the cytoplasm, but from inhibiting the mRNA expression of $\beta$-catenin. Our results indicate that berberine can be a potential chemoprevention and chemotherapy agent for human colon cancer by targeting Wnt/ $\beta$-catenin signaling.
\end{abstract}

\section{Introduction}

Colon cancer, which causes considerable morbidity and mortality, is one of the most common malignancies and primarily initiated by the abnormal activation of $\mathrm{Wnt} / \beta$ catenin signaling pathway (1). Although the treatment options have substantially increased and substantial benefits have been achieved for some patients, overall progress has been more modest than had been hoped (2). Thus, there is a great clinical need to explore new agents for the treatment of colon

Correspondence to: Dr Baicheng He, Department of Pharmacology, Chongqing Medical University, No. 1 of Yixueyuan Road, Yuzhong District, Chongqing 400016, P.R. China

E-mail: hebaicheng99@yahoo.com

Key words: berberine, colon cancer, proliferation inhibition, Wnt/ $\beta$ catenin signaling cancer. Herbal and natural products are valuable resources for anticancer drugs $(3,4)$. Plant derived active components, their semi-synthetic and synthetic analogs have served as one of the major sources for anticancer drugs (5-8). Some plant derived compounds have been used for anticancer drugs for a few years (6), including vinblastine, vincristine, etoposide, teniposide, taxol, and camptothecin. Thus, natural products acted as a major role in cancer chemotherapy for the past decades (6).

It has been reported that Chinese herb Coptis chinensis was a promising anticancer agent, of which the most active ingredient is berberine. In fact, berberine, an isoquinoline alkaline, has been used as anti-microbial, anti-diarrheal and anti-inflammatory agent for thousands of years (9). Because of its low toxicity and low cost, there has recently been considerable interest in the possible use of berberine in the treatment of human cancers. Several studies suggest that berberine can inhibit cell proliferation, also it has been reported that berberine can inhibit carcinogen, such as $\mathrm{DMH}$, induced formation of aberrant crypt foci (ACF) in the rat colon, which is usually considered to be preneoplastic lesions of colon mucosa. However, the exact mechanism is not fully understood yet.

We investigated the antiproliferation effects of berberine on human colon cancer cells, as well as the possible molecular basis underlying the effects. Our results strongly indicate that the proliferation inhibitory effect of berberine on colon cancer cells can be mediated by blocking Wnt/ $\beta$-catenin signaling transduction, which may be processed at least through down regulating the mRNA expression of $\beta$-catenin.

\section{Materials and methods}

Chemicals and drug preparations. Berberine was kindly provided by the 8th pharmaceutical manufacturer in Chengdu, China. The HCT116 cell line was kindly provided by Dr Bert Vogelstein of the Johns Hopkins Oncology Center (Baltimore, MD, USA) and Dr T.-C. He of the University of Chicago (Chicago, IL, USA). Berberine was dissolved in dimethyl sulfoxide (DMSO) for in vitro test, or prepared with $0.5 \%$ carboxymethylcellulose sodium (CMC-Na) as suspension for in vivo experiments. Antibodies were purchased from Santa Cruz Biotechnology. Cells were maintained in the Dulbecco's modified Eagle's medium (DMEM) with $10 \%$ fetal bovine serum (FBS), $100 \mathrm{U} / \mathrm{ml}$ of penicillin and $100 \mu \mathrm{g} / \mathrm{ml}$ of streptomycin at $37^{\circ} \mathrm{C}$ in $5 \% \mathrm{CO}_{2}$. 
Crystal violet viability assay. Crystal violet assay was conducted as described (10). Briefly, HCT116 cells were seeded in 24-well plates and treated with different concentrations of berberine. At 24, 48 or $72 \mathrm{~h}$ after treatment, cells were washed carefully with cold phosphate-buffered saline (PBS) $\left(4^{\circ} \mathrm{C}\right)$ and stained with $0.5 \%$ crystal violet formalin solution at room temperature for $20 \mathrm{~min}$. The stained cells were washed with tape water and air dried for taking image. For quantification, crystal violet in the stained cells was extracted with $1 \mathrm{ml}$ $20 \%$ acetic acid at room temperature for $20 \mathrm{~min}$ with shaking. A total of $100 \mu \mathrm{l}$ were taken out and added to $1 \mathrm{ml} \mathrm{ddH_{2 }} \mathrm{O}$. Absorbance at $570 \mathrm{~nm}$ was measured $(11,12)$. Each assay was done in triplicate.

Hoechst apoptosis staining. Cells were plated in 24-well plates at a subconfluent condition and were treated with different concentrations of berberine or DMSO. After being maintained at $37^{\circ} \mathrm{C}$ in $5 \% \mathrm{CO}_{2}$ for $72 \mathrm{~h}$, cells were collected and stained with Hoechst 33258 to visualize the apoptotic cells under fluorescence microscopy as reported (13). Each assay was done in triplicate.

Flow cytometric analysis for apoptosis and cell cycle arrest. Sub-confluent HCT116 cells were seeded in 6-well plates and treated with different concentrations of berberine or DMSO as vehicle control for $24 \mathrm{~h}$. Then, cells were collected and washed with cold PBS $\left(4^{\circ} \mathrm{C}\right)$, followed by incubating with annexin V-eGFP and propidium iodide (PI) as described in the introduction of the kits (\#KGA104, KeyGen Biotech, Nanjing, China). The stained cells were analyzed by fluorescence activated cell sorting (FACS). The number of 20,000 events was acquired and the cells were properly gated for analysis for apoptosis. For cell cycle analysis, treated the cells with different concentration of berberine $(20,40$, or $80 \mu \mathrm{M})$ for $24 \mathrm{~h}$. Then, cells were harvested, washed with PBS, fixed with cold $\left(4^{\circ} \mathrm{C}\right) 70 \%$ ethanol, washed with $50 \%$ and $30 \%$ ethanol, and PBS finally; Stained with $1 \mathrm{ml}$ of $20 \mathrm{mg} / \mathrm{ml}$ PI containing RNase $(1 \mathrm{mg} / \mathrm{ml})$ in PBS for $30 \mathrm{~min}$ followed by FACS for cycle analysis. Each assay was done in triplicate.

Preventive effect of berberine on colon cancer formation in in vivo model. The colon cancer model used in this study was initialized by subcutaneous injection of DMH plus $1 \%$ dextran sodium sulfate (DSS) as reported (14). Female 100 SpragueDawely rats weighing $140 \pm 10 \mathrm{~g}$ were ordered from the Animal Centre of Chongqing Medical University (Chongqing, China). All experiments were approved by Institutional Animal Care and Use Committee (IACUC) of Chongqing Medical University. Rats were given three subcutaneous injections of DMH $(40 \mathrm{mg} / \mathrm{kg}$ ) into the groin per week (the control group was given the same volume normal saline), followed by free access to drinking water containing $1 \%$ DSS for one week, changing to regular water and food in the 3rd week. At the end of the 3rd week, the DMH treated rats were divided into 3 groups randomly (25 each group) and treated with either different doses of berberine (120 and $240 \mathrm{mg} / \mathrm{kg}$ ) or solvent by intragastric administration, five times a week up to the 20th week. The rat body weight was measured every week from the 1 st week. At the end of 10th week, 10 rats of each group were sacrificed to detect the formation of ACF with methylene blue staining and to count the number of ACF under a microscope. At the end of 20th week, all rest rats were sacrificed to check the formation of colon cancer and retrieved the tumor mass for histological evaluation.

Western blot assay. Sub-confluent HCT116 cells were seeded in 6-well plates, then treated with different concentrations of berberine $(20,40$ or $80 \mu \mathrm{M})$ and DMSO was introduced as vehicle control for 12 and $24 \mathrm{~h}$. For total protein level assay, cells were washed with cold PBS $\left(4^{\circ} \mathrm{C}\right)$ and lysed in $300 \mu 1$ lysis buffer. For nucleus fraction protein extraction, the protein was harvested as per kit introductions (\#78833, Pierce Biotechnology, Inc., Rockford, IL, USA). Cell lysates were boiled for $10 \mathrm{~min}$, the total protein concentration of each sample was determined by BCA, then subjected SDS-PAGE and transfered to polyvinylidene fluoride (PVDF) membranes. The membranes were immunoblotted with primary antibodies, incubated with HRP conjugated second antibodies; Finally, developed with SuperSignal West Femto Chemiluminescent substrate (\#34095, Pierce). Each assay was done in triplicate.

Reverse transcription and polymerase chain reaction analysis. Sub-confluent HCT116 cells were seeded in T25 flasks and treated with different concentrations of berberine (20, 40 or $80 \mu \mathrm{M}$ ) for 12 and $24 \mathrm{~h}$. The total RNA were extracted with Trizol reagent (\#R0016, Invitrogen Life Technologies, Carlsbad, CA, USA), followed by reverse transcription (RT) for the cDNA. Then, the cDNAs were used as templates for detecting the expression level of interesting gene by polymerase chain reaction (PCR). The primers used were the following: $\beta$-catenin, forward 5'-CTGCAGGGGTCCTCTGTG-3', reverse 5'-TGCATATGTCGCCACACC-3'; GAPDH, 5'-CAG CGACACCCACTCCTC-3', reverse 5'-TGAGGTCCACCA CCCTGT-3'. Each assay was done in triplicate.

Recombinant adenovirus constructs for $\beta$-catenin over expression and knockdown. Recombinant adenoviruses expressing $\beta$-catenin and small interference RNA fragments were generated following the AdEasy system (15). Briefly, the coding region sequence of $\beta$-catenin was amplified with PCR, the interference small RNA fragments were designed with online free software from Dharmacon RNAi Technologies. The fragments were sub-cloned into a shuttle vector for recombinant adenovirus generation following the protocol of AdEasy system. The recombinant adenovirus is designated as Ad-BC and Ad-siBC. An analogous recombinant adenovirus expressing green fluorescent protein (GFP) was used as vector control (Ad-GFP).

Luciferase reporter assay. Firefly luciferase reporter assay was carried out as follows. Cells were seeded in T25 flasks and transfected with $3.0 \mu \mathrm{g}$ per flask of pTOP-Luc ( $\beta$-catenin/TCF4 reporter plasmid) or pGL3-Luc (positive control plasmid) using lipofectamine (\#11668019, Invitrogen). Twelve hours later, cells were replanted in 24-well plates and treated with different concentrations of berberine $(20,40$, or $80 \mu \mathrm{M})$ or DMSO as control. Twenty-four hours later, cells were lysed and subjected to luciferase activity assays following the manual of the kit (\#TM040, Promega Corporation, Madison, WI, USA). Luciferase activity was normalized by total cellular 

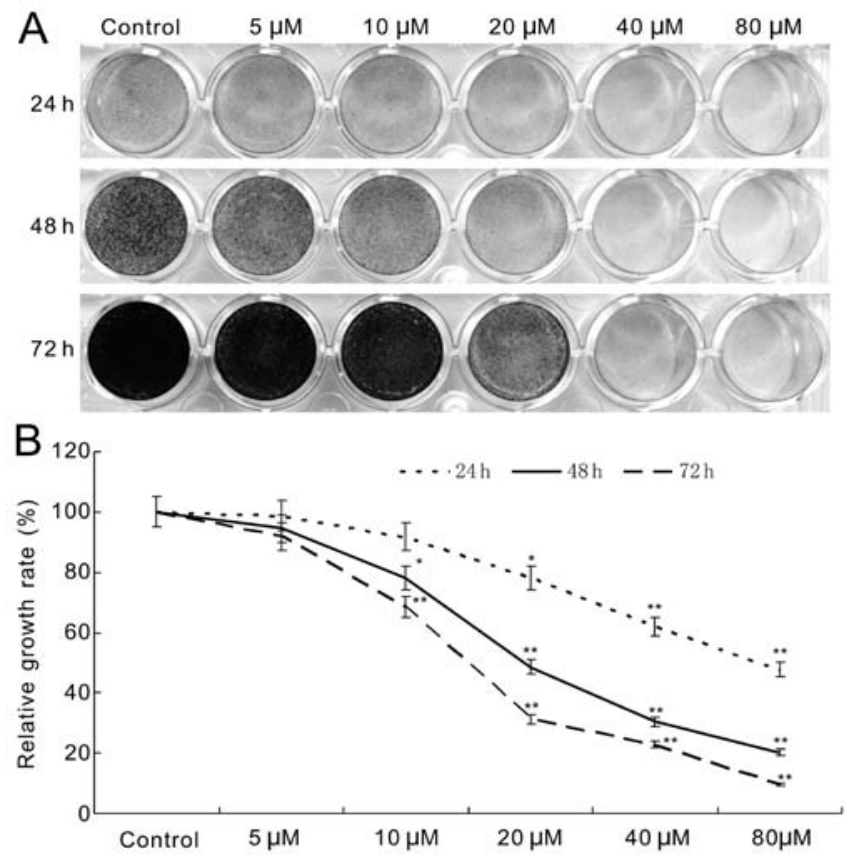

Figure 1. Berberine inhibits the proliferation of human colon cancer cells. Exponentially growing human colon cancer cells HCT116 were seeded in 24-well plates, and treated with berberine as the indicated concentrations. At 24,48 and $72 \mathrm{~h}$ after treatment, the cells were stained with crystal violet (A). (B) The quantification result. Each condition was done in triplicate. ${ }^{*} \mathrm{P}<0.05$, compared with control; ${ }^{* *} \mathrm{P}<0.01$, compared with control.

protein concentrations of the samples. Each assay was done in triplicate. Reporter activities are expressed as the mean \pm SD.

Statistical analysis. Microsoft Excel was employed to calculate the standard deviations. The differences were analyzed using the Student's t-test.

\section{Results}

Berberine inhibits the proliferation in HCT116 cells. To validate that berberine can function as a novel chemotherapeutic agent for human colon cancers, we first tested the proliferation inhibitory effect of berberine on human colon cancer cells with crystal violet staining. The result shows that berberine can inhibit the proliferation of HCT116 cells effectively in a concentration-dependent fashion (Fig. 1A), even at the minimum concentration of $10 \mu \mathrm{M}$. Fig. 1B shows the quantification results.

Berberine induces apoptosis in HCT116 cells. We next investigated whether berberine can induce colon cancer cells to undergo apoptosis. Hoechst 33258 staining result shows that the bright blue (apoptotic cells) in berberine treated group are more pronounced than that of control group (Fig. 2A), so does the caspase- 3 protein level at $24 \mathrm{~h}$ after berberine treatment (Fig. 2B). The FACS result shows the apoptotic cell rate increased in a concentration-dependent fashion (Fig. 2C). All the data indicate that berberine is capable of inducing apoptosis, a characteristic shared by most of the agents currently used for chemotherapy.

Berberine prevents the colon cancer formation induced by $D M H$. After the in vitro test, we focused on validating the chemoprevention effect of berberine on colon cancer formation induced by DMH in vivo. Our results show that the body weight of the rats from berberine treated group was much heavier than that from the model group at the corresponding time points, but no difference was seen between berberine treated group and the solvent control group (Fig. 3A). In our experiments, no $\mathrm{ACF}$ or colon cancer was found in the solvent control group; the number of ACF per rat in berberine treated groups was decreased comparing with the model group (Fig. 3B), and the colon cancer incidence of model group was much higher than that of the berberine treated groups (Fig. 3C).
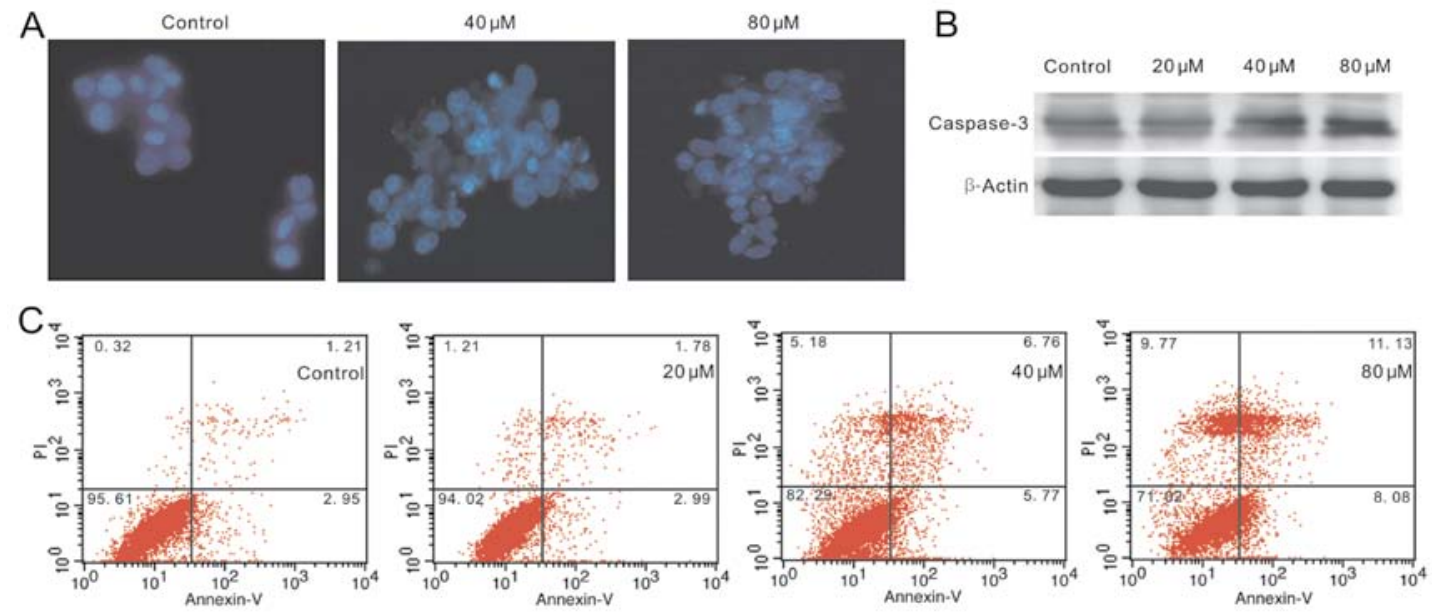

Figure 2. Berberine induces apoptosis in human colon cancer cells. (A) The Hoechst 33258 staining results. Cells were seeded in 24 -well plates and treated with indicated concentration of berberine or solvent for $72 \mathrm{~h}$, then harvested and stained with Hoechst 33258. (B) Berberine increases the protein level of caspase-3. Cells were seeded in 6-well plates and treated with the indicated concentration of berberine or solvent for $12 \mathrm{~h}$, then harvested for Western blot assay. (C) FACS analysis of apoptosis induced by berberine. Cells were seeded in 6-well plates, and treated with the indicated concentration of berberine or solvent for $72 \mathrm{~h}$, then collected and stained for FACS. Each assay condition was done in triplicate. 

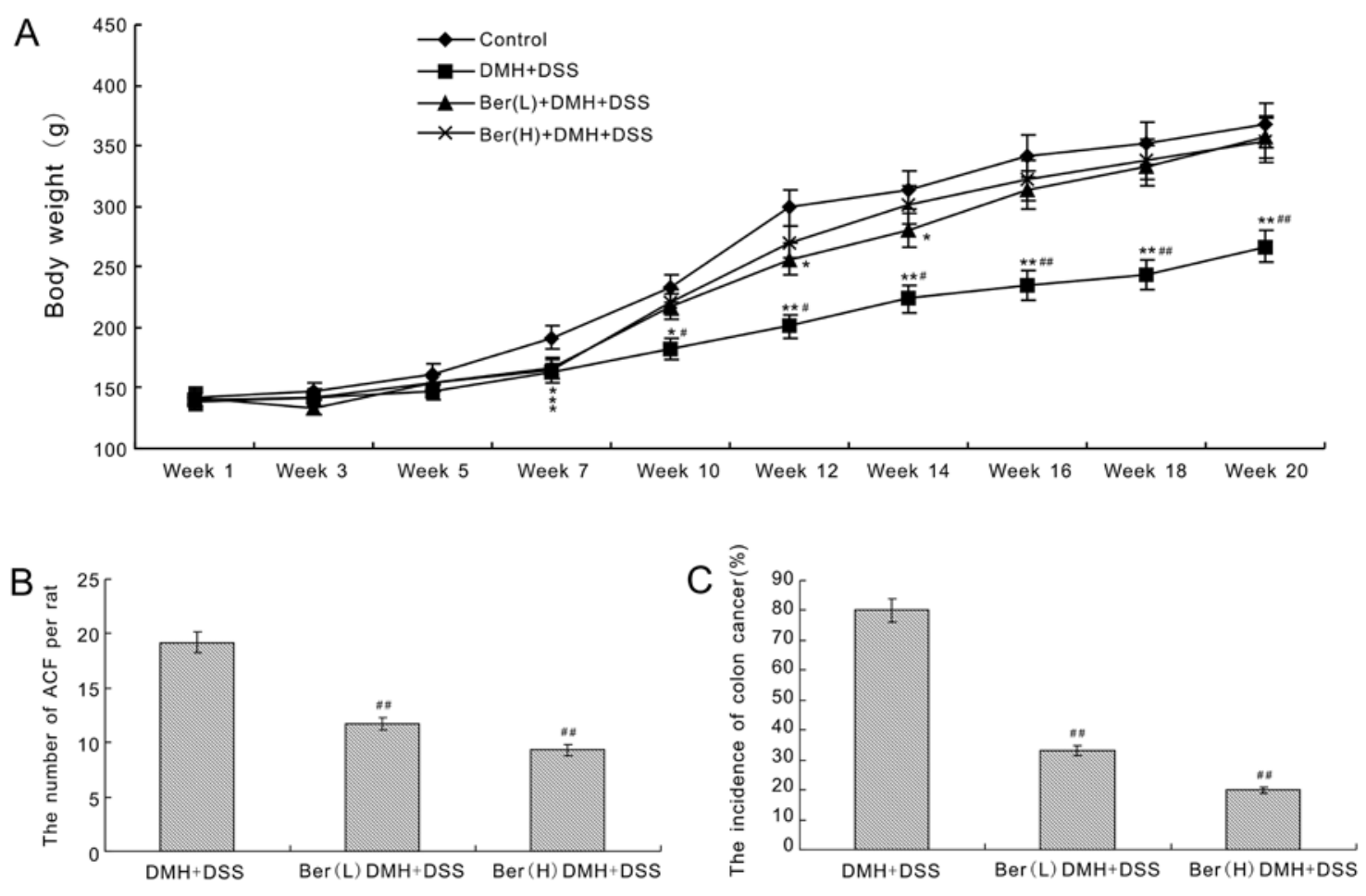

Figure 3. Berberine inhibits the ACF formation and colon cancer incidence initiated by DMH. Rat colon cancers were initialized by subcutaneous injection of DMH (see detail in Materials and methods) and then treated with different doses of berberine or solvent. (A) The body weight change results of rat (Ber, berberine; L, low; H, high). "P<0.05, compared with solvent control; ${ }^{* *} \mathrm{P}<0.01$, compared with solvent control; " $\mathrm{P}<0.05$, compared with the model group; ${ }^{\# \#} \mathrm{P}<0.01$, compared with the model. (B) The number of ACF per rat at 10 weeks. ${ }^{\# \#} \mathrm{P}<0.01$, compared with the model (mean $\left.\pm \mathrm{SD}, \mathrm{n}=10\right)$. (C) The colon cancer incidence of each group at 20 weeks. ${ }^{\# \#} \mathrm{P}<0.01$, compared with the model group $(\mathrm{n}=15)$.
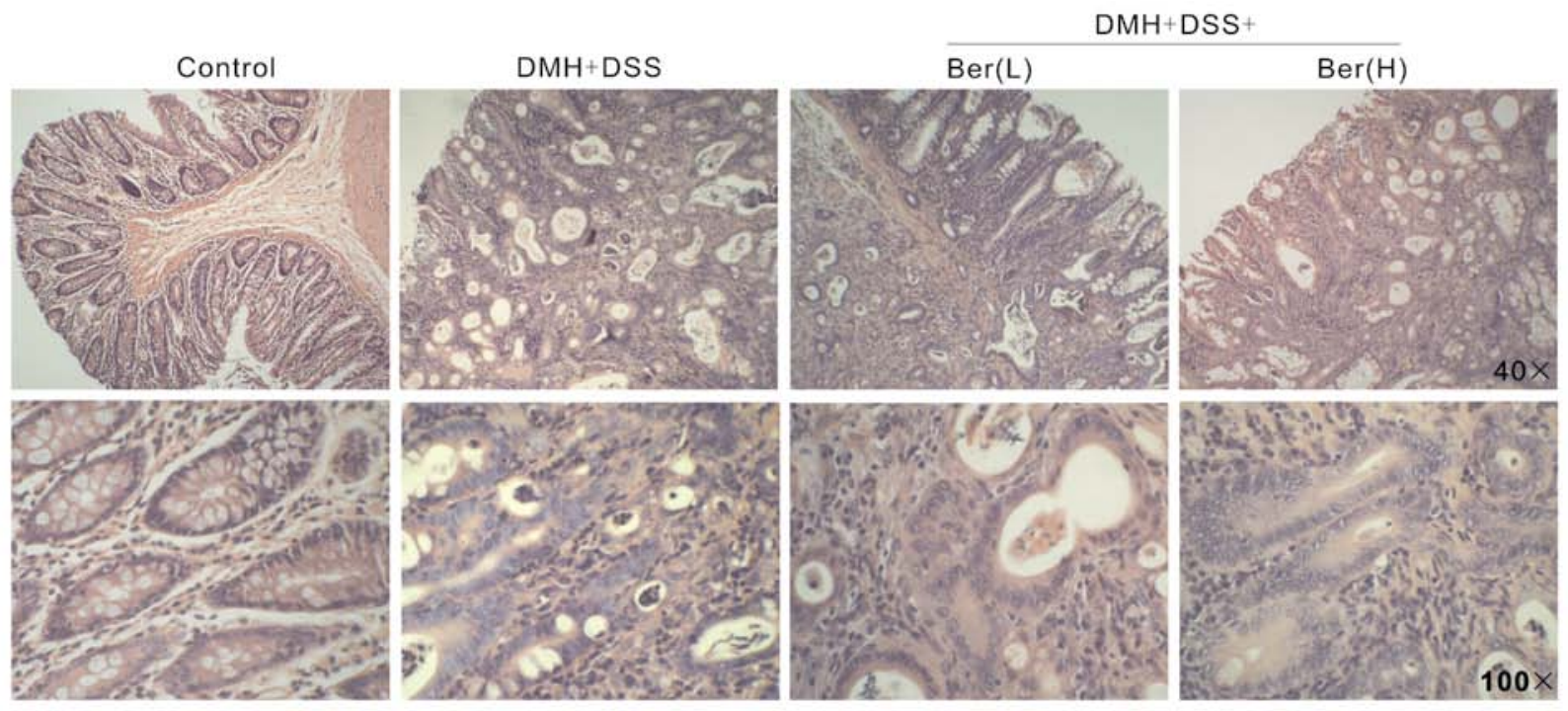

Figure 4. Berberine decreases the colon cancer formation induced by DMH. H\&E staining shows the colon cancer initiated by DMH and DSS in rat. Tumor masses retrieved from rat colon were fixed and paraffin embedded. Sections were used for H\&E staining. Original magnification, x40 and x100 (Ber, berberine; L, low; H, high).

The H\&E staining results indicate that colon adenocarcinoma was formed in all groups except the solvent control group (control). The cancer in model group was more aggressive than that of berberine treated groups, which invaded even to serosa and almost penetrating through the bowl tissue; the normal crypt structure mostly disappeared and the cancer cells were different in size and morphology. However, the cancer cells in berberine treated groups were located nearly to mucous layer with little change in size and morphology, especially in the group treated with high dose of berberine (Fig. 4). 
A
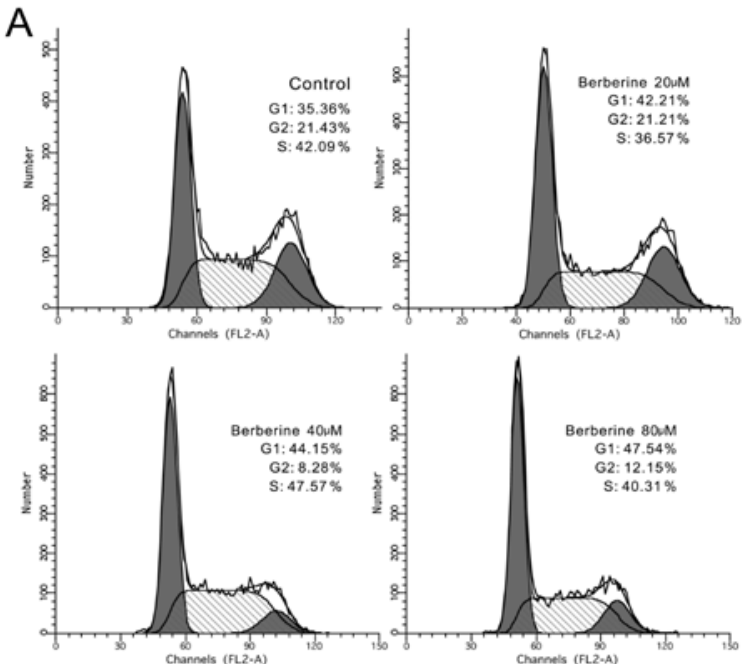

$\mathrm{B}$

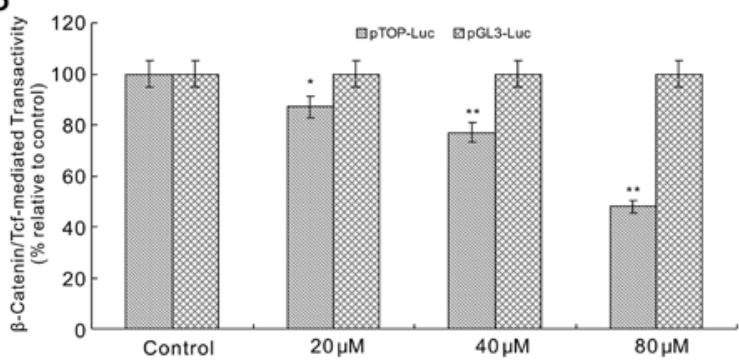

Figure 5. Berberine induces cell cycle arrest and inhibits $\beta$-catenin/TCF transcription activities in colon cancer cells. (A) Berberine induces cell cycle arrest at G1 phase in colon cancer cells. (B) Berberine inhibits $\beta$-catenin/ TCF transcription activity. ${ }^{*} \mathrm{P}<0.05$, compared with control; ${ }^{* *} \mathrm{P}<0.01$, compared with control.
Berberine arrests the cycle at G1 phase and inhibits the Wnt/ $\beta$ catenin signaling in human colon cancer. To understand the mechanism of berberine-induced proliferation inhibition and apoptosis in human colon cancer cells, we explored whether these function were associated with the cell cycle arrest. The results showed that the cells in G1 phase of berberine treated groups increased compared to that of the model group in a concentration-dependent manner (Fig. 5A). This indicates that berberine can arrest the cell cycle at G1 phase in human colon cancer cells.

Cell cycle control is a pivotal event controlled by many essential signaling pathways. Wnt/ $\beta$-catenin signaling is one of these pathways (16), and the aberrant activation of Wnt/ $\beta$ catenin signaling plays a critical role in the development of colorectal tumorigenesis (1). Therefore, we determined whether berberine targets Wnt/ $\beta$-catenin signaling to fulfil its function. We used pTOP-luc reporter assay to test the $\beta$-catenin/Tcf transcriptional activity in HCT116 cells treated with different concentrations of berberine. The result shows that berberine can effectively inhibit the luciferase activities of pTOP-Luc reporter (Fig. 5B). This suggests that berberine can inhibit the activation of Wnt/ $/$-catenin signaling.

Berberine inhibits $\beta$-catenin expression in colon cancer. $\beta$-catenin is a hub mediator for the activation of $\mathrm{Wnt} / \beta$-catenin signaling, which is usually dependent on the nucleus translocation of $\beta$-catenin from the cytoplasm. To investigate how berberine inactivates the Wnt/ $\beta$-catenin signaling, we first employed Western blot assay to detect the $\beta$-catenin protein level in the cytoplasm, nucleus and the whole cell. The result
A
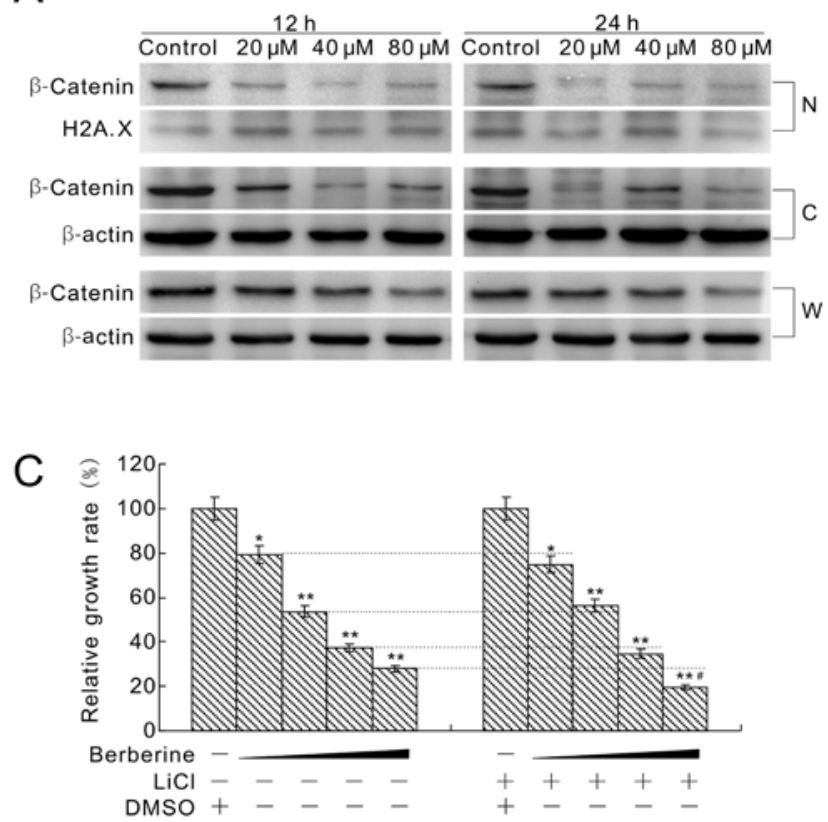

B

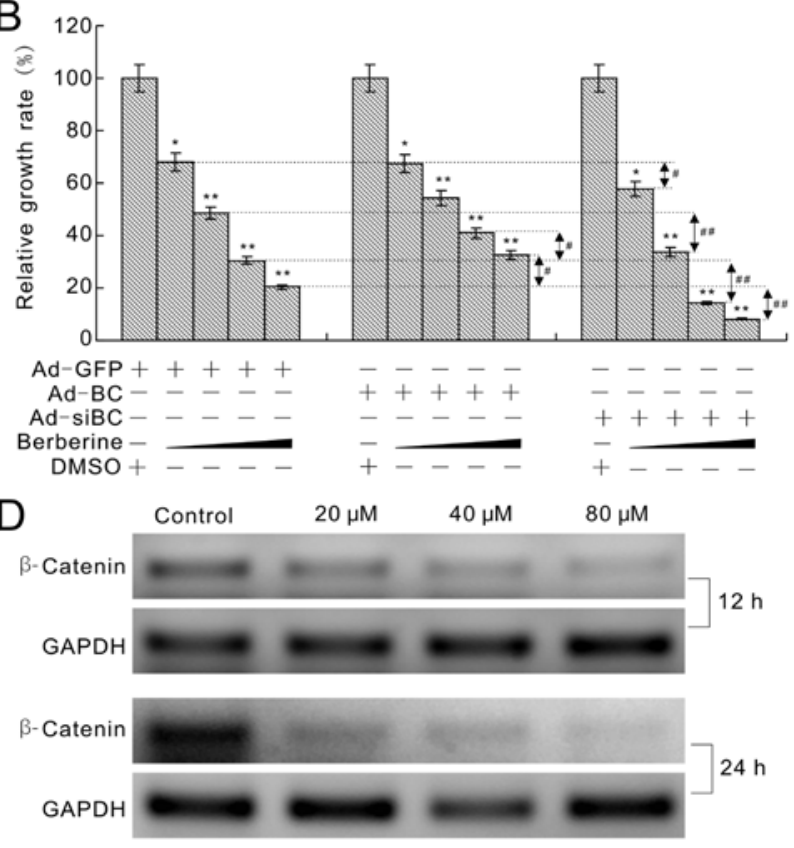

Figure 6. Berberine targets the Wnt/ $\beta$-catenin pathway for the proliferation inhibitory effect in human colon cancer cells. (A) Berberine decreases the protein level of $\beta$-catenin in the nucleus, cytoplasm and the whole cell (N, nucleus; $\mathrm{C}$, cytoplasm; W, whole cell). (B) The effect of exogenous expression or knockdown of $\beta$-catenin on the proliferation inhibitory effect of berberine in colon cancer cells. ${ }^{*} \mathrm{P}<0.05$, compared with control; ${ }^{* *} \mathrm{P}<0.01$, compared with control; ${ }^{\#} \mathrm{P}<0.05$, compared with GFP group; ${ }^{\#} \mathrm{P}<0.01$, compared with GFP group. (C) The effect of LiCl on the proliferation inhibitory effect of berberine in colon cancer. ${ }^{*} \mathrm{P}<0.05$, compared with control; ${ }^{* *} \mathrm{P}<0.01$, compared with control; ${ }^{\#} \mathrm{P}<0.05$, compared with corresponding treatment without LiCl. (D) Berberine down regulates the mRNA expression of $\beta$-catenin in colon cancer cells. Each assay condition was carried out in triplicate. 
indicates that berberine can decrease the $\beta$-catenin protein level not only in the nucleus, but also in the cytoplasm and the whole cell after the treatment with berberine for 12 or $24 \mathrm{~h}$ (Fig. 6A). To validate the role of $\beta$-catenin in the proliferation inhibitory effect of berberine on colon cancer cells, we tested the effects of exogenous expression or knockdown of $\beta$-catenin on the proliferation inhibitory effect of berberine in colon cancer cells. We found that exogenous expression of $\beta$-catenin can attenuate the growth inhibitory function of berberine, but knockdown of $\beta$-catenin can enhance this function in HCT116 cells (Fig. 6B), suggesting that down-regulation of $\beta$-catenin plays an important role in the function of berberine in colon cancer cells. It is unknown how beberine down regulates the $\beta$-catenin in cells. The stability of $\beta$-catenin in cells is associated with the complex formation of axin/APC/GSK-3 $\beta$. With the formation of this complex, $\beta$-catenin will be phosphorylated and then committed to degradation, which leads to the inactivation of $\mathrm{Wnt} / \beta$-catenin signaling. It was reported that lithium chloride can inhibit the phosphorylation of GSK-3 $\beta$ to activate the Wnt signaling (17). Thus, we introduced lithium chloride to inhibit GSK-3 $\beta$ to prevent the formation of axin/ APC/GSK-3 $\beta$ complex, but this cannot reverse the proliferation inhibitory effect of berberine on colon cancer cells (Fig. 6C). This indicates that the decrease of $\beta$-catenin protein level in cells may not result from the degradation initialized by the complex. Through further analysis with RT-PCR, we found that berberine can down-regulate the mRNA expression of $\beta$-catenin with a concentration-dependent phenotype (Fig. 6D).

The above data indicate that the proliferation inhibitory effect of berberine on colon cancer cells may result from the inactivation of $\mathrm{Wnt} / \beta$-catenin signaling by inhibiting the expression of $\beta$-catenin.

\section{Discussion}

Colon cancer is one of the most common malignancies, the abnormal activation of $\mathrm{Wnt} / \beta$-catenin signaling pathway (1) plays a critical role in its development. With our expanding knowledge, the management of colon cancer has made substantial development in the past decades, but the prognosis remains poor. Thus, there is a great clinical need to develop new treatment strategies or agents for the treatment of colon cancer. In this study, we investigated the antiproliferation effect of berberine in human colon cancers. We found that berberine can inhibit cell proliferation of colon cancer cells, as well as prevent colon cancer formation induced by $\mathrm{DMH}$. The inhibitory effect of berberine on colon cancer cells may be mediated in part by inactivating the Wnt/ $\beta$ catenin signaling through down-regulation of the expression of $\beta$-catenin.

Berberine is the major component of the tranditional Chinese medicine Coptis chinensis, which has been used as an anti-microbial, anti-diarrheal and anti-inflammatory agent in China for thousands of years (9). Because of its low toxicity and low cost, berberine has gained considerable interest in the possibility to treat human cancers. Several studies suggest that berberine can inhibit the proliferation of cancer cells $(18,19)$. Although the therapeutic benefits and reliable biosafety profiles of berberine have been well recognized, the molecular bases of its actions remain largely undefined. A few studies have attempted to clarify the possible molecular mechanism of berberine underlying these functions: Berberine can induce cell cycle arrest and apoptosis in murine 3T3 cells in a dose- dependent fashion (20), inhibit COX-2 transcriptional activity in colon cancer cells (21), and inhibit the activity of the AP-1 transcription factor (22). Several studies also demonstrated that berberine can inhibit arylamin $\mathrm{N}$-acetyltransferase activity that is required for the metabolic conversion of arylamine carcinogens (23-26). Consistent with its long-standing liver protective effects, berberine has been shown to exhibit anticachectic effect in a colon cancer-bearing mouse model (25), and to induce the growth related gene rcl, in a rat hepatoma cell line (27). Recent reports indicate that p53 and p38 MAPK pathways are involved in berberine anticancer activity $(28,29)$. Although these studies have provided some understanding about the functions of berberine, the exact molecular mechanisms are unknown.

It was reported that the abnormal activation of Wnt signaling accounts for tumor initiation of $80-90 \%$ of all colon cancer cases (1). Wnt/ $\beta$-catenin has been shown to be one of the important targets for colon cancer chemoprevention. Berberine can inhibit carcinogen-induced formation of ACFs in the rat colon, which are usually considered to be preneoplastic lesions of colon mucosa (30). DMH-induced colon cancers are characterized by activating $\beta$-catenin mutations that are functionally equivalent to inactivating APC mutations $(31,32)$. Therefore, we propose that the effect of berberine on colon cancer cells may result from targenting Wnt/ $\beta$-catenin signaling, and validated this function of berberine in a $\mathrm{DMH}-$ induced colon cancer animal model.

Wnt/ $\beta$-catenin is an important signaling pathway for embryogenesis and cancer. $\beta$-catenin plays a pivotal role in this signaling. In the absence of Wnt ligands, axin, GSK-3 $\beta$ and protein APC can be assembled as a complex, which can promote the proteolytic degradation of $\beta$-catenin. In the presence of Wnt ligands, the complex is destroyed and the $\beta$-catenin become stable in the cytoplasm and translocates to the nucleus. Finally, $\beta$-catenin interacts with TCF/LEF transcription factors to regulate downstream gene expression. Lithium chloride can inhibit the phosphorylation of GSK-3 $\beta$ and activate the $\mathrm{Wnt} / \beta$-catenin signaling. Our results show that berberine can reduce the total protein level of $\beta$-catenin, as well as the $\beta$-catenin in the nucleus and cytoplasm, even at the concentration as low as $20 \mu \mathrm{M}$. Over-expression of $\beta$-catenin can attenuate the function of berberine, and knockdown of $\beta$-catenin can enhance the growth inhibitory effect of berberine. Combine berberine with lithium chloride can not reverse the proliferation inhibitory effect of berberine on HCT116 cells. Through further analysis, we found that berberine can inhibit the mRNA expression of $\beta$-catenin in a concentration-dependent manner.

Taken together, this study suggests that berberine can be used as a chemotherapy agent for human colon cancers. The proliferation inhibitory effect of berberine on colon cancer cells may be result from inactivating $\mathrm{Wnt} / \beta$-catenin signaling through inhibiting the expression of $\beta$-catenin with unkown mechanism, not by promoting the degradation of $\beta$-catenin. Future studies will be directed to unveil the exact mechanism 
of berberine on down-regulation of $\beta$-catenin expression, as well as combining berberine with other traditional chemotherapy agents to develop a novel therapy strategy for human colon cancers.

\section{Acknowledgements}

The authors thank Dr Bert Vogelstein (Johns Hopkins Oncology Center, Baltimore, MD, USA) and Dr T.-C. He (University of Chicago, IL, USA) for their kind provision of the HCT116 cells, pTOP-Luc and pGL3-Luc reporter vectors. This project was supported partly by the National Basic Research Program of China (2011CB70790) and Chongqing Science \& Technology Commission of China (CSTC 2011BB5129).

\section{References}

1. Kinzler KW and Vogelstein B: Lessons from hereditary colorectal cancer. Cell 87: 159-170, 1996.

2. Aggarwal $\mathrm{S}$ and Chu E: Current therapies for advanced colorectal cancer. Oncology 19: 589-595, 2005.

3. Cragg GM, Grothaus PG and Newman DJ: Impact of natural products on developing new anti-cancer agents. Chem Rev 109: 3012-3043, 2009.

4. Ji HF, Li XJ and Zhang HY: Natural products and drug discovery. Can thousands of years of ancient medical knowledge lead us to new and powerful drug combinations in the fight against cancer and dementia? EMBO Rep 10: 194-200, 2009.

5. da Rocha AB, Lopes RM and Schwartsmann G: Natural products in anticancer therapy. Curr Opin Pharmacol 1: 364-369, 2001.

6. Mann J: Natural products in cancer chemotherapy: past, present and future. Nat Rev Cancer 2: 143-148, 2002.

7. Koehn FE and Carter GT: The evolving role of natural products in drug discovery. Nat Rev Drug Discov 4: 206-220, 2005.

8. Corson TW and Crews CM: Molecular understanding and modern application of traditional medicines: triumphs and trials. Cell 130: 769-774, 2007.

9. Tang J,Feng Y, Tsao S, Wang N, Curtain R and Wang Y: Berberine and Coptidis Rhizoma as novel antineoplastic agents: A review of traditional use and biomedical investigations. J Ethnopharmacol 126: 5-17, 2009.

10. He BC, Chen L, Zuo GW, et al: Synergistic antitumor effect of the activated PPARgamma and retinoid receptors on human osteosarcoma. Clin Cancer Res 16: 2235-2245, 2010.

11. Ishiyama M, Tominaga H, Shiga M, Sasamoto K, Ohkura $Y$ and Ueno K: A combined assay of cell viability and in vitro cytotoxicity with a highly water-soluble tetrazolium salt, neutral red and crystal violet. Biol Pharm Bull 19: 1518-1520, 1996.

12. Stepanovic S, Vukovic D, Dakic I, Savic B and Svabic-Vlahovic M: A modified microtiter-plate test for quantification of staphylococcal biofilm formation. J Microbiol Methods 40: 175-179, 2000.

13. Haydon RC, Zhou L, Feng T, et al: Nuclear receptor agonists as potential differentiation therapy agents for human osteosarcoma. Clin Cancer Res 8: 1288-1294, 2002.

14. Onose J, Imai T, Hasumura M, Cho YM and Hirose M: A new medium-term rat colon bioassay applying neoplastic lesions as endpoints for detection of carcinogenesis modifiers - validation with known modifiers. Cancer Lett 232: 272-278, 2006.

15. He TC, Zhou S, da Costa LT, Yu J, Kinzler KW and Vogelstein B: A simplified system for generating recombinant adenoviruses. Proc Natl Acad Sci USA 95: 2509-2514, 1998.
16. Davidson $\mathrm{G}$ and Niehrs C: Emerging links between CDK cell cycle regulators and Wnt signaling. Trends Cell Biol 20: 453-460, 2010.

17. Silva AK, Yi H, Hayes SH, Seigel GM and Hackam AS: Lithium chloride regulates the proliferation of stem-like cells in retinoblastoma cell lines: a potential role for the canonical Wnt signaling pathway. Mol Vis 16: 36-45, 2010.

18. Mahata S, Bharti AC, Shukla S, Tyagi A, Husain SA and Das BC: Berberine modulates AP-1 activity to suppress HPV transcription and downstream signaling to induce growth arrest and apoptosis in cervical cancer cells. Mol Cancer 10: 39, 2011.

19. Liu Q, Jiang H, Liu Z, et al: Berberine radiosensitizes human esophageal cancer cells by downregulating homologous recombination repair protein RAD51. PLoS One 6: e23427, 2011.

20. Yang IW, Chou CC and Yung BY: Dose-dependent effects of berberine on cell cycle pause and apoptosis in Balb/c 3T3 cells. Naunyn Schmiedebergs Arch Pharmacol 354: 102-108, 1996.

21. Fukuda K, Hibiya Y, Mutoh M,Koshiji M, Akao S and Fujiwara H: Inhibition by berberine of cyclooxygenase-2 transcriptional activity in human colon cancer cells. J Ethnopharmacol 66: 227-233, 1999

22. Fukuda K, Hibiya Y, Mutoh M, Koshiji M, Akao S and Fujiwara $\mathrm{H}$ : Inhibition of activator protein 1 activity by berberine in human hepatoma cells. Planta Med 65: 381-383, 1999.

23. Wang DY, Yeh CC, Lee JH, Hung CF and Chung JG: Berberine inhibited arylamine $\mathrm{N}$-acetyltransferase activity and gene expression and DNA adduct formation in human malignant astrocytoma (G9T/VGH) and brain glioblastoma multiforms (GBM 8401) cells. Neurochem Res 27: 883-889, 2002.

24. Lin JG, Chung JG, Wu LT, Chen GW, Chang HL and Wang TF: Effects of berberine on arylamine $\mathrm{N}$-acetyltransferase activity in human colon tumor cells. Am J Chin Med 27: 265-275, 1999.

25. Iizuka N, Hazama S, Yoshimura K, et al: Anticachectic effects of the natural herb Coptidis rhizoma and berberine on mice bearing colon 26/clone 20 adenocarcinoma. Int J Cancer 99: 286-291, 2002.

26. Chung JG, Wu LT, Chu CB, et al: Effects of berberine on arylamine $\mathrm{N}$-acetyltransferase activity in human bladder tumour cells. Food Chem Toxicol 37: 319-326, 1999.

27. Chan CP, But PP and Ho JW: Induction of rcl, a novel growthrelated gene by coptidis rhizoma in rat H4IIE cells. Life Sci 70: 1691-1699, 2002

28. Zhang X, Gu L, Li J, et al: Degradation of MDM2 by the interaction between berberine and DAXX leads to potent apoptosis in MDM2-overexpressing cancer cells. Cancer Res 70: 9895-9904, 2010.

29. Hur JM, Hyun MS, Lim SY, Lee WY and Kim D: The combination of berberine and irradiation enhances anti-cancer effects via activation of p38 MAPK pathway and ROS generation in human hepatoma cells. J Cell Biochem 107: 955-964, 2009.

30. Fukutake M, Yokota S, Kawamura $\mathrm{H}$, et al: Inhibitory effect of Coptidis Rhizoma and Scutellariae Radix on azoxymethaneinduced aberrant crypt foci formation in rat colon. Biol Pharm Bull 21: 814-817, 1998.

31. Tucker E, Buda A, Janghra B, et al: Abnormalities of the cadherin-catenin complex in chemically-induced colorectal carcinogenesis. Proc Nutr Soc 62: 229-236, 2003.

32. Imai T, Fukuta K, Hasumura M, et al: Significance of inflammation-associated regenerative mucosa characterized by Paneth cell metaplasia and beta-catenin accumulation for the onset of colorectal carcinogenesis in rats initiated with 1,2-dimethylhydrazine. Carcinogenesis 28: 2199-2206, 2007. 